\title{
AVALIAÇÃO ERGONÔMICA DO AMBIENTE CONSTRUIDO: ESTUDO NA CENTRAL DE MATERIAIS E ESTERILIZAÇÃO DE UM HOSPITAL UNIVERSITÁRIO
}

\section{ERGONOMIC BUILT INVIRONMENT EVALUATION: STUDY IN THE CENTRAL OF MATERIALS AND STERILIZATION OF A UNIVERSITY HOSPITAL}

\author{
Alaíde Farias, Enfermeira (1); \\ Marcelo Gomes, Pedagogo (2); \\ Marilande Silva, Enfermeira (3); \\ Waldelourdes de Melo, Enfermeira (4); \\ Vilma Villarouco, Dr ${ }^{\mathrm{a}}$ em engenharia de produção (5). \\ 1. Universidade Federal de Pernambuco. \\ e-mail:alaideff@hotmail.com \\ 2. Universidade Federal de Pernambuc. \\ e-mail:marceloh2@yahoo.com.br \\ 3. Universidade Federal de Pernambuco. \\ e-mail: marilande_andrade@hotmail.com \\ 4. Universidade Federal de Pernambuco. \\ e-mail:walmelosoutomaior@gmail.com \\ 5. Universidade Federal de Pernambuco. \\ e-mail:villarouco@hotmail.com
}

Palavras-chave: Ergonomia, Central de Materiais e Esterilização, Ergonomia do Ambiente Construído.

Este artigo relata uma avaliação ergonômica do ambiente construído na Central de Materiais e Esterilização de um Hospital Universitário em Recife, foi aplicada a Metodologia Ergonômica para o Ambiente Construído (MEAC), proposta por Villarouco (2008). Após análise dos dados, foi possível identificar alguns problemas e as recomendações foram sugeridas. 


\begin{abstract}
$16^{\circ}$ Ergodesign - Congresso Internacional de Ergonomia e Usabilidade de Interfaces Humano Tecnológica: Produto, Informações Ambientes Construídos e Transporte

$16^{\circ}$ USIHC - Congresso Internacional de Ergonomia e Usabilidade de Interfaces Humano Computador

CINAHPA | 2017 - Congresso Internacional de Ambientes Hipermídia para Aprendizagem.
\end{abstract}

Keywords: Ergonomics, Unit of processing of materials sterilized, Ergonomics of the Built Environment.

This article reports an ergonomic evaluation of the environment built in a Materials and Sterilization Center of a University Hospital in Recife, was applied to the Ergonomic Methodology for the Built Environment (MEAC), proposed by Villarouco (2008). After analyzing the data, it was possible to identify some problems and the recommendations were suggested.

\section{Introdução}

A Central de Materiais e Esterilização (CME) é definida pelo Ministério da Saúde (1987), como "conjunto de elementos destinados à recepção e expurgo, preparo, esterilização, guarda e distribuição do material não caracterizado como uso único para as unidades de estabelecimento de saúde".

A Resolução RDC $n^{\circ} .307$, de 14 de novembro de 2002, considera a CME uma unidade de apoio técnico, que tem como finalidade o fornecimento de materiais médico-hospitalares adequadamente processados, proporcionando assim, condições para $\mathrm{o}$ atendimento direto e a assistência à saúde dos indivíduos enfermos e sadios.

Assim, o estudo da ergonomia visa melhorar a adaptação do trabalho ao homem, sendo este multidisciplinar, envolve aspectos físicos e organizacionais. O trabalho diário realizado em condições inadequadas pode levar ao surgimento de problemas de saúde (IIDA, 2005).

Portanto, o presente estudo foi realizado com o objetivo de avaliar o ambiente da CME de um Hospital Universitário sob o foco ergonômico, a partir da Metodologia Ergonômica para o Ambiente Construído (MEAC), proposta por Villarouco (2008).

\section{Metodologia}

Trata-se de uma pesquisa exploratória e qualitativa, de cunho descritivo. A população estudada foi de 19 profissionais de enfermagem, de um universo de 49 , de ambos os sexos. A pesquisa foi realizada de outubro a novembro de 2016. Para a realização da análise, optou-se pela MEAC.

Desse modo, a MEAC é constituída por 2 (duas) fases; uma de ordem física e outra perceptiva, com geração de recomendações ergonômicas projetuais ou atitudinais para o ambiente. A primeira fase se divide em 3 (três) etapas: (i) Análise Global do Ambiente, (ii) Configuração Ambiental, (iii) Avaliação do Ambiente em Uso, com objetivo de entender e avaliar o sistema homem-atividadeambiente, com a identificação de elementos facilitadores e inibidores das atividades. Para entender de que maneira o usuário percebe sua interação com o ambiente, a fase de ordem perceptiva utiliza técnicas da Psicologia Ambiental, tais como Mapa Mental ou Cognitivo, Constelação de Atributos, Poema dos Desejos, questionário, entre outros (PAIVA et al, 2016).

\section{Análise Ergonômica}

\subsection{Análise Global do Ambiente}

A CME está situada no $3^{\circ}$ pavimento do hospital, numa área construída de $346 \mathrm{~m}^{2}, 11$ ambientes, 16 postos de trabalho, é um setor fechado e o acesso é limitado.

A equipe é de 49 trabalhadores (enfermeiros, técnicos e auxiliares de enfermagem, auxiliar administrativo e auxiliares de serviços gerais).

O ambiente é limpo, apresenta má conservação dos equipamentos e mobiliários, a iluminação é deficiente, a acústica é aceitável e a temperatura é inconstante, mudando conforme o posto de trabalho.

A NR 32, a RDC 50 de 2002 da ANVISA, e o Ministério da Saúde são diretrizes regulamentadoras de Normas Específicas para o funcionamento da CME.

\subsection{Identificação da Configuração Ambiental}

A edificação é de $346 \mathrm{~m}^{2}$ de área construída, piso em placa de vinílico de cor clara, paredes com
Realização:
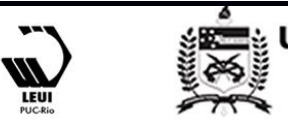
$16^{\circ}$ Ergodesign - Congresso Internacional de Ergonomia e Usabilidade de Interfaces Humano Tecnológica: Produto, Informações Ambientes Construídos e Transporte

$16^{\circ}$ USIHC - Congresso Internacional de Ergonomia e Usabilidade de Interfaces Humano Computador

CINAHPA | 2017 - Congresso Internacional de Ambientes Hipermídia para Aprendizagem.

azulejos e pintura acrílica semi-brilho de cor clara e teto com forro removível branco. Possui 11 (onze) ambientes, sendo: entrada/recepção, expurgo, área de preparo e esterilização, sala de depósito, sala de repouso, sala administrativa, copa, vestiário e WC masculino, vestiário e WC feminino, área de armazenamento e distribuição e o hall (entrega de materiais).

Consideramos para análise apenas um ambiente: 0 expurgo. Nele existe um elevador (monta carga) para recebimento de artigos sujos, um condicionador de ar Split, um balcão de inox duplo e centralizado, com armário inferior ao mesmo, três cadeiras giratórias desgastadas, um armário de parede, dois balcões com cubas em inox lateralizados, uma pia para limpeza de materiais de serviços gerais, e um balcão em inox fixo para liberação dos artigos limpos, uma máquina termodesinfectadora e uma lavadora ultrassônica (quebradas).

$\mathrm{Na}$ área de preparo e esterilização tem um condicionador de ar Split, seis mesas dispostas paralelamente para secagem, preparo e embalagem dos artigos, uma pistola de ar comprimido para secagem dos canulados, três seladoras para papel grau cirúrgico, uma incubadora para testes biológicos, uma mesa em fórmica para preparo dos artigos de produção e uma mesa grande em fórmica para apoio à esterilização e armários para guarda de materiais de consumo. Três autoclaves de barreira (duas quebradas) apenas uma funcionando. Um dispensador de álcool gel.

Na sala administrativa tem três mesas com computadores e um balcão de fórmica lateralizado ao longo da sala, um condicionador de ar Split e dois armários para guarda de documentos.

$\mathrm{Na}$ área de armazenamento e distribuição existe uma pia para higienização das mãos, estantes paralelas para guarda de artigos, um elevador (monta carga) para distribuição de artigos para os blocos cirúrgicos, um balcão com gavetas e uma janela acima do balcão para distribuição dos artigos para os demais setores.

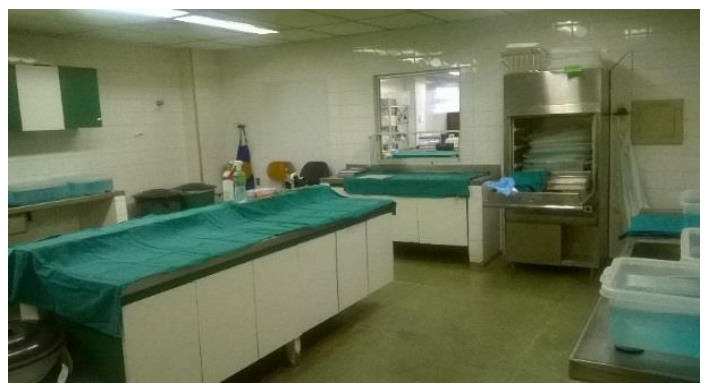

Figura 1. Ambiente analisado: Expurgo Fonte: Arquivo dos pesquisadores

\section{PLANTA BAIXA DO CME}

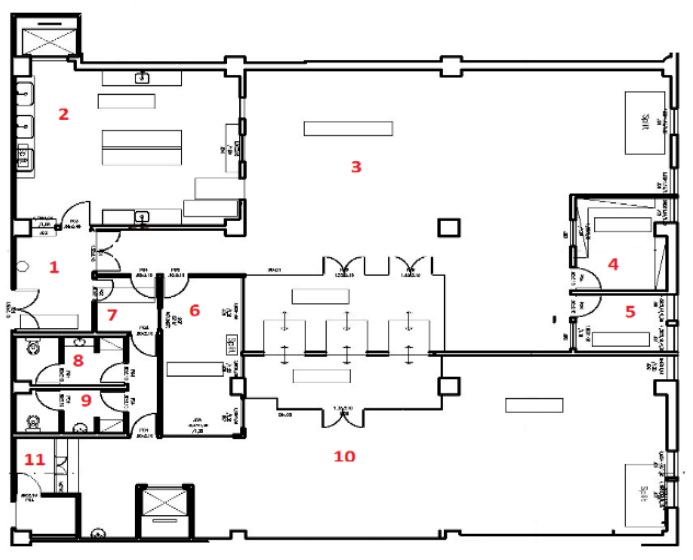

Figura 2. Planta baixa do CME

Fonte: Arquivo dos pesquisadores

\section{1-Entrada/recepção; 2-expurgo; 3-área} preparo/esterilização; 4-sala depósito; 5-sala repouso; 6-sala administrativa; 7-copa; 8vestiário/WC feminino; 9-vestiário/WC masculino; 10-sala de armazenamento e distribuição; 11-hall (entrega de materiais).

\section{Acessibilidade e Desenho Universal}

A Norma Técnica utilizada para o parâmetro de avaliação dos aspectos de acessibilidade foi NBR 9050/2015 agregando aspectos de segurança, não tem rota de fuga e os extintores de incêndio estão sem sinalização e em locais inacessíveis e faltando alguns. $\mathrm{O}$ acesso a CME pode ser por escadas ou elevadores com sinalização visual e sonora. 

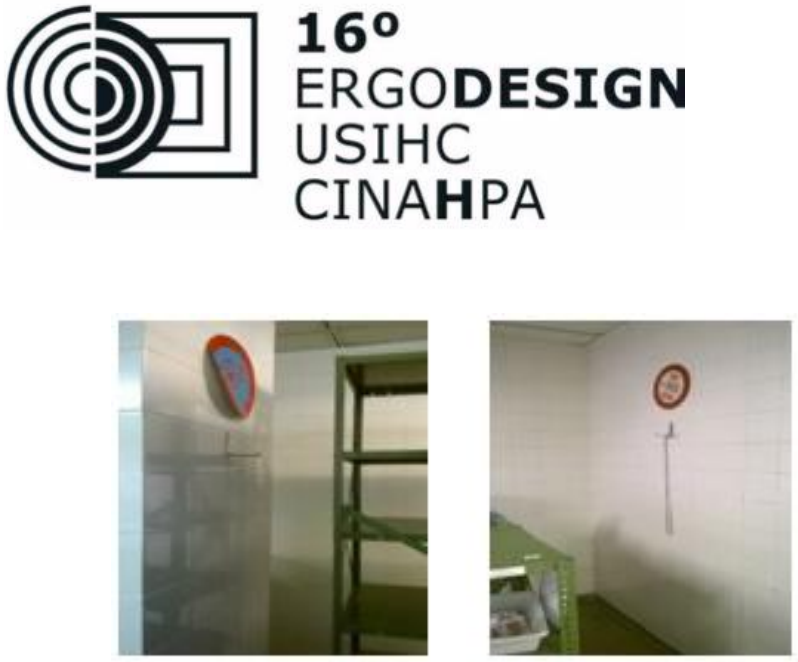

Figura 3. Local dos extintores na área de armazenamento e distribuição

Fonte: Arquivo dos pesquisadores

\section{Avaliação do Conforto Lumínico}

A iluminação é composta por luminárias fluorescentes de 40W. Utilizamos o aplicativo Lux Meter, para celular, a fim de medir o nível de iluminância, os dados são apresentados no quadro a seguir e comparados com os níveis indicados pela NBR 5413/1992.

\begin{tabular}{|c|c|c|c|c|}
\hline \multirow{2}{*}{ AMBIENTE } & \multirow{2}{*}{ PONTO } & $\begin{array}{l}\text { MED } \\
\text { (lux) }\end{array}$ & $\begin{array}{l}\text { MED } \\
\text { (lux) }\end{array}$ & \multirow{2}{*}{$\begin{array}{l}\text { NBR } \\
5413 \\
\text { (lux) }\end{array}$} \\
\hline & & $08: 00 \mathrm{~h}$ & $16: 00 \mathrm{~h}$ & \\
\hline Expurgo & 2 & 125,1 & 125,1 & 150 \\
\hline
\end{tabular}

Quadro 1. Dados para medição do conforto lumínico

No ambiente escolhido para o estudo (Expurgo), o nível de iluminância estava não conforme com a norma.

\section{Avaliação do Conforto Acústico}

Realizamos medições do ruído interno para analisar o conforto acústico e verificar se os resultados estariam em conformidade com a NBR 10152 da ABNT, 2000. O nível de ruído foi medido com o aplicativo Sound Meter, para celular.

\begin{tabular}{|c|l|l|l|l|}
\hline \multirow{2}{*}{ AMBIENTE } & \multirow{2}{*}{ PONTO } & $\begin{array}{l}\text { MED } \\
(\mathrm{dB})\end{array}$ & $\begin{array}{l}\text { MED } \\
(\mathrm{dB})\end{array}$ & $\begin{array}{l}\text { NBR } \\
10152 \\
\end{array}$ \\
\cline { 3 - 5 } & $08: 00 \mathrm{~h}$ & $16: 00 \mathrm{~h}$ & $(\mathrm{~dB})$ \\
\hline Expurgo & 2 & 72,9 & 64,1 & $\begin{array}{l}45 \mathrm{a} \\
55\end{array}$ \\
\hline
\end{tabular}

Quadro 2. Dados para medição do conforto acústico

No ambiente analisado, a acústica estava não conforme com a norma, bem acima do limite, devido ao fluxo de pessoas circulando e equipamentos em funcionamento. $16^{\circ}$ Ergodesign - Congresso Internacional de Ergonomia e Usabilidade de Interfaces Humano Tecnológica: Produto, Informações Ambientes Construídos e Transporte

$16^{\circ}$ USIHC - Congresso Internacional de Ergonomia e Usabilidade de Interfaces Humano Computador

CINAHPA | 2017 - Congresso Internacional de Ambientes Hipermídia para Aprendizagem.

\section{Avaliação do conforto térmico}

O expurgo possui um split de 1.800 BTUs. Utilizamos o aplicativo thermometer, para celular, para verificação do nível de temperatura do ambiente em estudo.

\begin{tabular}{|l|l|l|l|l|}
\hline \multirow{2}{*}{ AMBIENTE } & \multirow{2}{*}{ PONTO } & $\begin{array}{l}\text { MED } \\
\left({ }^{\circ} \mathrm{C}\right)\end{array}$ & $\begin{array}{l}\text { MED } \\
\left({ }^{\circ} \mathrm{C}\right)\end{array}$ & \multirow{2}{*}{ NR 17 } \\
\cline { 3 - 4 } & $08: 00 \mathrm{~h}$ & $16: 00 \mathrm{~h}$ & \\
\hline Expurgo & 2 & 28,3 & 28,3 & $20-23^{\circ} \mathrm{C}$ \\
\hline
\end{tabular}

Quadro 3. Dados para medição do conforto térmico

O ambiente está não conforme com a norma. As janelas internas (de recebimento e de entrega de materiais) ficam abertas, favorecendo a não conformidade.

\subsection{Avaliação do Ambiente em Uso}

\section{Avaliação do Ambiente em uso no Desempenho de suas Atividades:}

\section{FLUXOGRAMA}

O fluxo de uma CME deve ser contínuo e unidirecional, evitando o cruzamento de artigos sujos, limpos e esterilizados, bem como evitar que o trabalhador da área contaminada transite pelas áreas limpas e vice-versa.

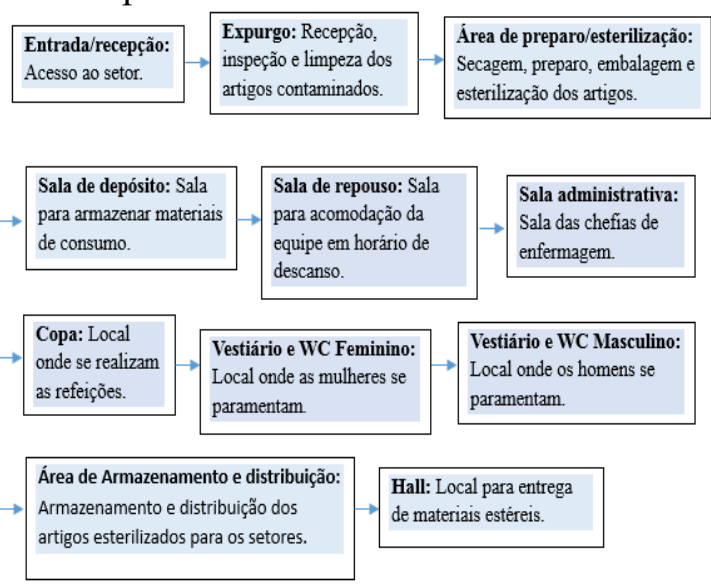

Figura 4. Fluxograma da CME

Através da recepção são entregues os artigos contaminados para serem conferidos e iniciar o processo de lavagem no expurgo, em seguida seguem para a área de preparo, onde são inspecionados novamente, secos e preparados com embalagens para esterilização, depois seguem para 


\section{$16^{\circ}$}

\section{ERGODESIGN USIHC CINAHPA}

esterilização, ao término, são armazenados para posterior distribuição aos setores de origem.

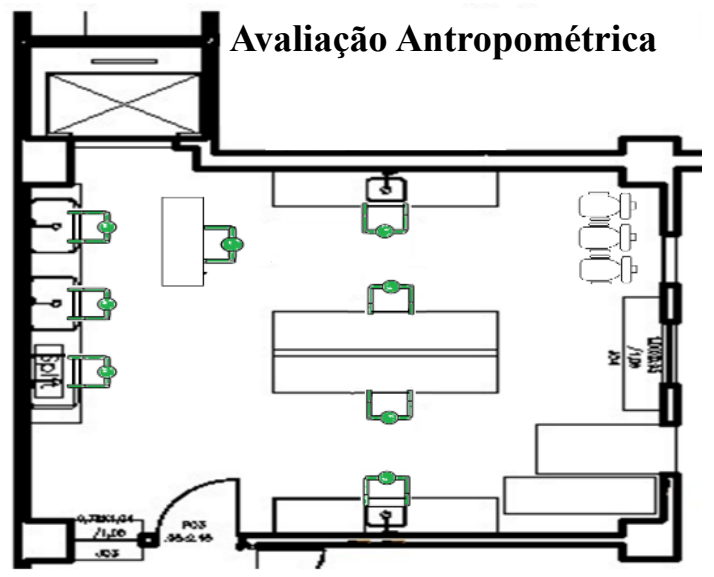

Figura 5. Avaliação antropométrica do expurgo

No layout do Expurgo, a circulação é bem favorecida, porém, deveria estar melhor disposto em relação ao design do mobiliário. Os balcões são altos, os usuários têm que trabalhar em pé, e conforme as variáveis antropométricas dos profissionais, eles ficam em desconforto.

Observamos desconforto aos profissionais no recebimento dos materiais através do monta carga, (a última prateleira é muito alta).

Como também, a falta de mesas com rodízios para transportar materiais pesados, causam desconforto aos profissionais.

Outra não conformidade, foram as máquinas que sempre estão quebradas e a lavagem é apenas manual, sobrecarregando os profissionais.

Observamos também a falta de cadeiras para os profissionais quando necessitam de uma pausa.

\subsection{Percepção Ambiental do Usuário}

Para percepção ambiental, o usuário é considerado único, pois experimenta sensações variadas e as compreende conforme seus sentidos e suas condições a nível fisiológico, psicológico e físico (FLORES e ULBRICHT, 2008).

Dessa forma, foi aplicada a Constelação de Atributos idealizada por Moles (1968), ferramenta que possui vantagens como método de coleta simples, rápida e descentralizada; maior liberdade $16^{\circ}$ Ergodesign - Congresso Internacional de Ergonomia e Usabilidade de Interfaces Humano Tecnológica: Produto, Informações Ambientes Construídos e Transporte

$16^{\circ}$ USIHC - Congresso Internacional de Ergonomia e Usabilidade de Interfaces Humano Computador

CINAHPA | 2017 - Congresso Internacional de Ambientes Hipermídia para Aprendizagem.

de expressão dos usuários; representação gráfica e legível; respostas a duas perguntas abertas e distintas (uma de caráter imaginário e outra de caráter real) (TAVARES et al, 2016).

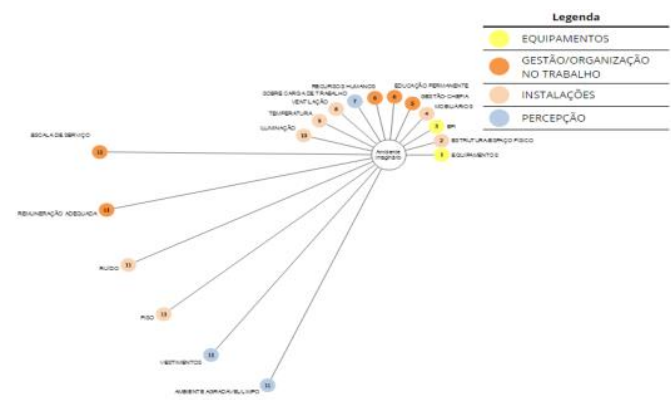

Figura 6. Constelação de atributos "Ideal"

$\mathrm{Na}$ figura acima, avaliamos a imagem simbólica do indivíduo frente ao ambiente Ideal, através da pergunta Quando você pensa em uma "Central de Materiais e Esterilização" que idéias ou imagens vem à mente? As respostas evidenciaram a percepção de um ambiente ideal bem estruturado e organizado, com equipamentos de proteção individuais adequados, mobiliários ergonomicamente adaptados, uma gestão moderna, educação permanente presente, RH suficiente evitando a sobre carga de trabalho, temperatura, ruído, iluminação conforme as Normas Regulamentadoras e uma remuneração que satisfaça a classe, como uma escala de serviço mais humanizada que reflete em um melhor atendimento ao usuário no que diz respeito a realização das tarefas.

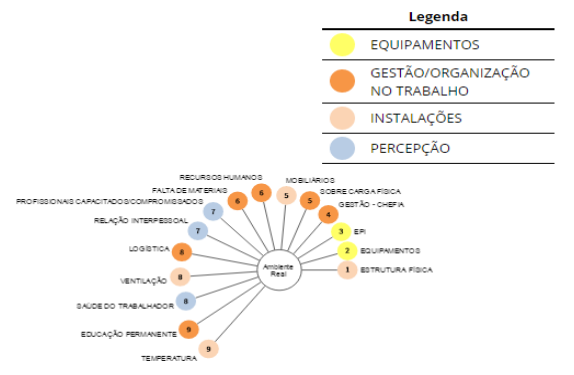

Figura 7. Constelação de Atributos "Real"

Foi avaliada a imagem real do indivíduo frente ao ambiente Real, através da pergunta "Quando você pensa nesta "Central de Materiais e Esterilização" que idéias ou imagens vem à mente? Ao 


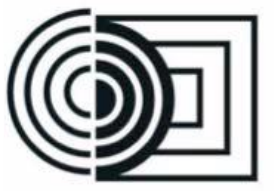

analisarmos as respostas, verificamos que os funcionários são compromissados e capacitados, solicitam uma melhoria na estrutura física, aquisição de equipamentos e mobiliários, uma chefia com gestão humanizada e melhora na relação interpessoal, percebem que a logística precisa ser melhorada, existe sobrecarga física de trabalho, o recurso humano é insuficiente e falta materiais, o que contribui negativamente para a realização de suas atividades.

\subsection{Diagnóstico Ergonômico do Ambiente e Recomendações}

\begin{tabular}{|l|l|}
\hline DIAGNOSTICOS & RECOMENDAÇÖES \\
\hline $\begin{array}{l}\text { Extintores sem } \\
\text { sinalização, em falta e } \\
\text { com acesso obstruido. }\end{array}$ & $\begin{array}{l}\text { Providenciar os extintores } \\
\text { que faltam, sinalizar } \\
\text { adequadamente e liberar o } \\
\text { acesso aos mesmos. }\end{array}$ \\
\hline $\begin{array}{l}\text { Expurgo e área de } \\
\text { preparo sem pia. }\end{array}$ & $\begin{array}{l}\text { Instalação de uma pia para } \\
\text { higienização das mãos no } \\
\text { expurgo e na área de preparo. }\end{array}$ \\
\hline $\begin{array}{l}\text { Mobiliários e } \\
\text { equipamentos antigos } \\
\text { e ultrapassados. }\end{array}$ & $\begin{array}{l}\text { Aquisição de mobiliários e } \\
\text { equipamentos adequados. }\end{array}$ \\
\hline RH insuficiente. & Redimensionamento de RH. \\
\hline $\begin{array}{l}\text { Educação permanente } \\
\text { deficiente. }\end{array}$ & $\begin{array}{l}\text { Promover cursos e } \\
\text { treinamentos aos } \\
\text { trabalhadores. }\end{array}$ \\
\hline $\begin{array}{l}\text { Ambientes com } \\
\text { lâmpadas queimadas } \\
\text { ou danificadas. }\end{array}$ & $\begin{array}{l}\text { Providenciar reposição das } \\
\text { lâmpadas. }\end{array}$ \\
\hline $\begin{array}{l}\text { Ambiente com } \\
\text { temperatura fora das } \\
\text { Normas } \\
\text { Regulamentadoras. }\end{array}$ & $\begin{array}{l}\text { Providenciar climatização } \\
\text { adequada para os ambientes } \\
\text { em questão. }\end{array}$ \\
\hline
\end{tabular}

Quadro 4. Diagnósticos e recomendações

A CME atende as necessidades a que se propõe, por sua dimensão, teria um potencial para uma maior produtividade se fossem feitos os ajustes necessários. $\mathrm{O}$ expurgo foi considerado bem estruturado e respeita ao preconizado para as variáveis ambientais e de conforto, necessita de modernização, revisão dos mobiliários existentes e aquisição de equipamentos. Apresenta pontos críticos, em alguns ambientes a norma não é atendida. Com intuito de eliminar ou diminuir os problemas identificados, e portanto melhorar o layout, o desenvolvimento das atividades e a satisfação dos usuários, construiu-se, a partir dos problemas identificados pela percepção dos pesquisadores e dos dados levantados pelas $16^{\circ}$ Ergodesign - Congresso Internacional de Ergonomia e Usabilidade de Interfaces Humano Tecnológica: Produto, Informações Ambientes Construídos e Transporte

$16^{\circ}$ USIHC - Congresso Internacional de Ergonomia e Usabilidade de Interfaces Humano Computador

CINAHPA | 2017 - Congresso Internacional de Ambientes Hipermídia para Aprendizagem.

entrevistas e questionários o quadro acima com os respectivos problemas e as recomendações.

\section{Conclusão}

Os resultados apontam que a ergonomia, área de conhecimento multidisciplinar, pode contribuir de forma positiva para a melhoria da qualidade de vida dos trabalhadores e usuários de serviços, apontando soluções ou minimizando e prevenindo danos à saúde dos profissionais.

Espera-se que os resultados alcançados com esta pesquisa possam colaborar para um olhar atento às necessidades da CME, ressaltando a importância de proporcionar recursos a fim de transformá-la em um ambiente de trabalho adequado.

\section{Referências}

ASSOCIAÇÃO BRASILEIRA DE NORMAS TÉCNICAS. NBR 9050: Acessibilidade a edificações, mobiliário espaços e equipamento urbanos. Rio de Janeiro, 2015.

ASSOCIAÇÃO BRASILEIRA DE NORMAS TÉCNICAS. NBR 10152: níveis de ruído para conforto acústico. Rio de Janeiro, 2002.4 p.

ASSOCIAÇÃO BRASILEIRA DE NORMAS TÉCNICAS. NBR 5413: iluminância de interiores. Rio de Janeiro, 1992. 13 p.

BRASIL. Ministério do Trabalho e Emprego. NR 32 - Ergonomia. Brasília: 2007.

FLORES, A. R. B.; ULBRICHT, V. R.; ZANCHETT, P. S. Terceira idade e moradia. In: Anais do XV Congresso Brasileiro de Ergonomia-ABERGO. Porto Seguro-Bahia, 2008.

IIDA, Itiro. Ergonomia: Projeto e produção. $2^{\mathrm{a}}$ ed. Rev. e ampl. São Paulo: Edgar Blucher, 2005.

PAIVA, M. M.; TAVARES, A. S.; OLIVEIRA, M.; VILLAROUCO, V. Análise Comparativa da Acessibilidade em ILPI's. Anais do I CONAERG. Recife, 2016.

TAVARES, A. S.; ALBUQUERQUE, L. W. N.; BARBOSA, A. H.; VILLAROUCO, V. Percepção 


\section{$16^{\circ}$}

ERGODESIGN USIHC CINAHPA $16^{\circ}$ Ergodesign - Congresso Internacional de Ergonomia e Usabilidade de Interfaces Humano Tecnológica: Produto, Informações Ambientes Construídos e Transporte

$16^{\circ}$ USIHC - Congresso Internacional de Ergonomia e Usabilidade de Interfaces Humano Computador

CINAHPA | 2017 - Congresso Internacional de Ambientes Hipermídia para Aprendizagem.

ambiental: A importância da opinião dos usuários na geração de recomendação para projetos de ambientes construídos. Anais do $\mathbf{X}$ Encontro Nacional de Ergonomia do Ambiente Construído, VII Seminário Brasileiro de Acessibilidade Integral. Recife, 2016.

VILLAROUCO, Vilma. O ambiente está adequado? In: Anais do I Encontro Nacional de Ergonomia do Ambiente Construído, II Seminário Brasileiro de Acessibilidade Integral. Recife, 2008. 